together in a short book - only 184 rather small thick pages despite the price - all that is known about the history, folklore, hunting, natural history and distribution of wild goats in Britain. Because little or no field work has been done on them, the natural history perforce remains mainly on the anecdotal level, but this after all is how our knowledge of all our wild animals began. Now that this book has drawn attention to it, may we hope that researchers will consider the wild goat in Britain a respectable animal to study.

For it has many fascinating aspects: how this originally domesticated animal escaped and established itself in hill districts, how it adapted itself to a strange environment, much cooler and wetter than its native Mediterranean; how its appearance, both horns and pelage, has changed over the years. In the complete list of known occurrences at the end, the destruction of all too many herds by ignorant and ill-informed people is chronicled. A little research might avoid these needless mindless occurrences, but such is the power of ignorance in the countryside that one wonders.

From the same publishers, who have a commendable policy of reprinting natural history classics, I am glad to see a new edition of Richard Perry's fine book based on his own field observations. This discursive observational type of writing, which began with Selous, seems almost to have ended with Perry. Nowadays the jargon of ethology is expected. There was a lot to be said for making one's book readable.

RICHARD FITTER

\title{
Pippa's Challenge, by Joy Adamson. Collins and Harvill, £2.75.
}

This is the follow up to The Spotted Sphinx in which Joy Adamson returned Pippa, a tame cheetah, to the wild, where she survived for a number of years and gave birth to four litters. The significance of Joy Adamson's findings are considerable, because, despite several hundred years of effort, man has had very poor success in getting captive cheetahs to reproduce. Now, when there is concern for the cheetah's survival in some parts of its range, and in nearly every zoo that keeps cheetahs, she has shown that transplanting them into wild country, protecting them only from man, can result in their reproducing.

However, it is one thing for a tame cheetah to be encouraged to bear young in a new and wild home, and quite another thing for the cubs to survive. Pippa's Challenge is the story of what happened to the cubs, how they grew up, learned to hunt, passed through the rigours of puberty, found mates and eventually brought forth new generations. It is a story of incredible insight into the lives of wild cheetahs and their day-to-day survival.

As with her other books, there is a strong personal involvement between what happens to her animals and what Joy Adamson both feels and does. After Pippa's death (from natural causes), for example, she makes a grave under Pippa's favoured tree; such emotional involvement has sometimes been criticised by the scientific community. However it is precisely because of her love for her animals that Joy Adamson is able to continue to persevere under the all-too-often frustrating conditions that working on big cats entails. Much as I would prefer more science, I know of few scientists, who, under similar circumstances, would be willing to follow around an expanding family of cheetahs for three generations. 